UNIVERSIDADE ESTADUAL DE FEIRA DE SANTANA

Autorizada pelo Decreto Federal no 77.496 de 27/04/76

PPPG

PRÓ-REITORIA DE PESQUISA E PÓS-GRADUAÇÃO

COORDENAÇÃO DE INICIAÇÃO CIENTÍFICA

XXIII SEMINÁRIO DE INICIAÇÃO CIENTÍFICA DA UEFS

SEMANA NACIONAL DE CIENTÍFICA E TECNOLÓGICA - 2019

\title{
DINÂMICA DO ESPELHO D’ÁGUA DO LAGO DE ITAPARICA-BA
}

\author{
Iolanda Santos de Castro'; Jocimara Souza Britto Lobão ${ }^{2}$ \\ 1. Bolsista FAPESB, Graduanda em Licenciatura em Geografia, Universidade Estadual de Feira de Santana, e-mail: \\ iolycastro@ hotmail.com \\ 2. Orientadora, Departamento de Ciências Humanas e Filosofia, Universidade Estadual de Feira de Santana, e-mail: \\ juci.lobao@gmail.com
}

PALAVRAS-CHAVE: Lago de Itaparica; MapBiomas; Uso e ocupação da terra

\section{INTRODUÇÃO}

A água é primordial para a vida, sendo, portanto, o ambiente aquático essencial e fundamental à existência humana e à manutenção dos ecossistemas do planeta (ESTEVES, 2011; CARDOSO et al., 2017). O aumento da demanda por energia tem motivado a construção de reservatórios para a acumulação de água para fins hidrelétricos. Todavia, esses reservatórios não servem apenas para energia, há outras finalidades como abastecimento humano, irrigação, pesca, recreação, dessedentação de animais e controle de enchentes.

A degradação crescente do meio ambiente, nos ecossistemas aquáticos, acarreta consequências graves à sociedade comprometendo as gerações futuras. $\mathrm{O}$ uso inadequado da água dos reservatórios brasileiros está sendo prejudicado pela falta de cumprimento das leis em vigor (MELO, 2007). Os reservatórios do Nordeste brasileiro evidenciam a necessidade de planos e ordenamento de um monitoramento mais efetivo, como exemplo o reservatório de Itaparica, área de estudo, localizado no sub-médio rio São Francisco.

O sensoriamento remoto disponibiliza maneiras e técnicas para o mapeamento dos ecossistemas aquáticos sendo usados, frequentemente, para análise espacial e temporal da dinâmica da água dos reservatórios (LOPES et al., 2015). Para controlar a dinâmica do espelho d'água do reservatório de Itaparica BA-PE, são necessários estudos de monitoramento, por meio de imagens obtidas pelo Landsat, que tem como fundamento avaliar a capacidade de manutenção da água ao longo do tempo, características limnológicas dos corpos d'água e o entendimento das consequências ambientais sobre o uso e ocupação do solo desta região, contribuindo assim para o manejo sustentável deste ecossistema aquático.

Diante do exposto, este estudo contribuiu para avaliar a dinâmica do espelho d'água do lago de Itaparica, a partir de dados do Projeto Anual Brasileiro de Mapeamento e Uso da Terra e do Solo (MapBiomas). Para a análise dos dados foi feito a quantificação da lâmina do espelho d'água do Lago de Itaparica, para assim, relacionar o uso e a cobertura da terra como o padrão de comportamento do reservatório numa série multitemporal de 1985- 2017.

\section{MATERIAL E MÉTODOS}

A área de estudo situa-se no Submédio São Francisco, na Bahia compreende parte dos municípios de Rodelas, Glória, Macururé, Abaré. Em Pernambuco, corresponde aos 
municípios de Floresta, Petrolândia, Itacuruba, Jatobá, Tacaratú e Belém do São Francisco, região a qual tem passado por diversas transformações devido a construção do complexo hidrelétrico e obras devido à integração da bacia.As análises estatísticas dos resultados foram feitas pelo algoritmo Land Change Modeler (LCM), o qual consiste numa modelagem cartográfica do potencial de transição. O uso de álgebra matricial, verifica-se as mudanças de uso e cobertura da terra, com dados quantificado e qualificado. Com a obtenção dos dados foi gerado mapas da área de ganhos e perdas, tanto em medidas de porcentagem e hectares com o intuito de verificar as mudanças ocorridas no tempo e espaço.

\section{RESULTADOS E/OU DISCUSSÃO}

Nos estudos sobre análise ambiental o Sensoriamento Remoto oferece várias técnicas de se monitorar o uso e ocupação da terra, sendo assim o monitoramento é importante para compreender como constituiu e expandiu a dinâmica do espelho d'água. Por meio dos dados da Plataforma MapBiomas, foi possível a realização do mapeamento do Lago de Itaparica numa série multitemporal de 1985-2017, por sua vez, a área de estudo apresentou variações significativas nos 33 anos analisados (Figura 1).

Figura 1 - Evolução de uso e cobertura da terra por hectare de 1985-2017

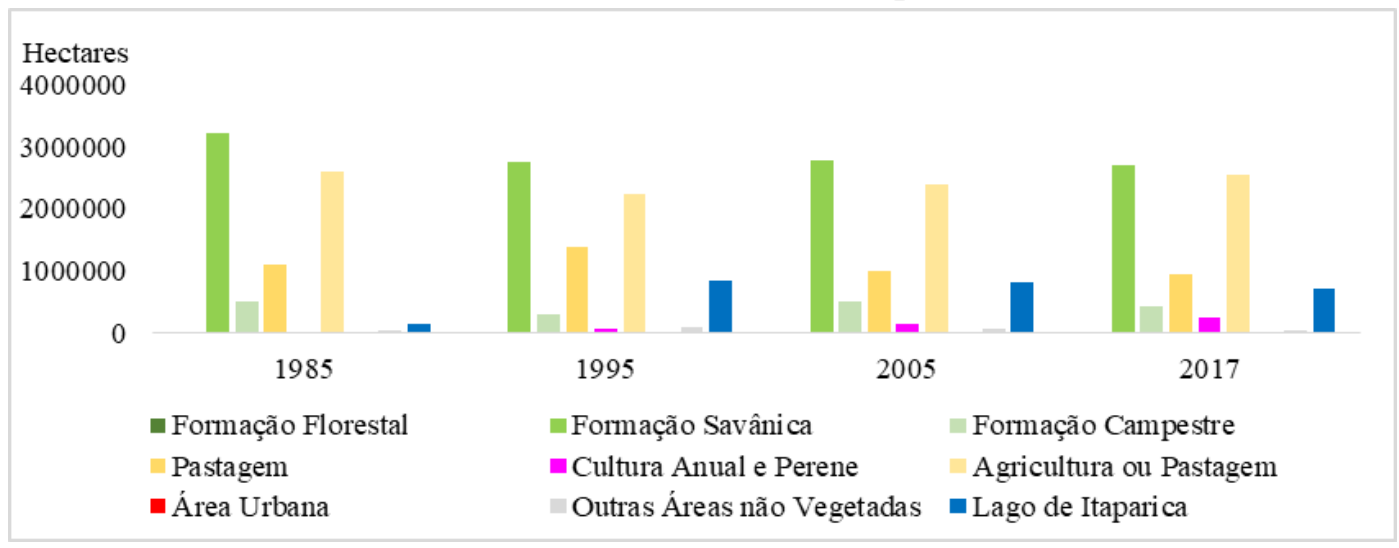

Elaboração: Iolanda Santos de Castro, 2019

Na análise em questão no ano de 1985 a Formação Savânica recobre a cima de 30 milhões de hectares da área de estudo, nesse ano não se tinha o represamento das águas do Lago. Para os pescadores da região, a pesca se dava em quantidade menor, sendo, apenas, para o sustento das famílias localizadas às margens do Sub-médio São Francisco.

A partir do ano de 1995 foi notório o aumento significativo dos cultivos, pois na região há uma predominância de várias culturas como Cocos nucifera L., Cucumis melo, Manihot esculenta, Citrullus lanatus, Allium cepa, Citrus limon, dentre outros.

Nos dias atuais, os pescadores da região utilizam arpão e bombas para pesca, práticas estas consideradas como um crime ambiental, entretanto, os pescadores da região defendem o represamento das águas por trazer emprego para a comunidade. Segundo eles, com o represamento veio uma organização social, que trouxe para comunidade, colônias, associações e sindicatos de forma a organizar as comunidades ribeirinhas.

Em todos os anos verifica-se aumento significativo no uso da terra em detrimento da caatinga (Figura 2). Nesta perspectiva, há uma série de danos atribuídos no ambiente; 
retenção da capacidade do solo, redução de biomassa e alteração das características do ecossistema, o que confirma a pressão da sociedade sobre os recursos e ecossistemas naturais, principalmente, no uso e manejo inadequado da terra, desmatamento, queimadas, pecuária extensiva.

Figura 2 - Distribuição percentual das classes de uso e ocupação da terra no período de 1985 a 2017

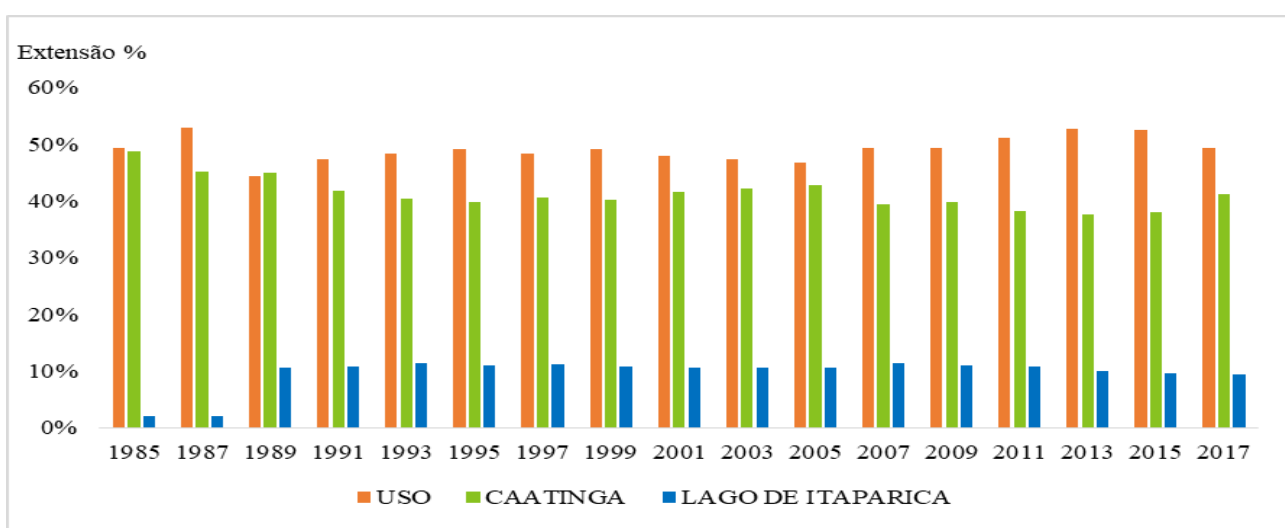

Elaboração: Iolanda Santos de Castro, 2019

As mudanças encontradas da área de estudo, no último ano da pesquisa evidencia um aumento significativo da dinâmica do espelho d'água e da classe da agropecuária, com muitas culturas às margens do lago de Itaparica. Na classe de formação florestal nota-se que não houve uma preservação, isto ocorre devido ao desmatamento intensivo em toda região.

Por meio dos dados do resultante do LCM verificou-se os valores de ganho e perda para cada classe: formação florestal perdeu $74,21 \%$ e ganhou $66,53 \%$, formação savânica perdeu $29,61 \%$ e ganhou $16,48 \%$, formação campestre perdeu $63,33 \%$ e ganhou $57,39 \%$, pastagem perdeu $75,52 \%$ e ganhou 71,59, agropecuária perdeu 44,83 e ganhou 47,89\%, infraestrutura urbana perdeu 47,67 e ganhou 45,27, outra área não vegetada perdeu $87,06 \%$ e ganhou 86,73, finalmente, o rio não perdeu, ganhou 81,16\% (Figura 3).

Figura 3 - Classes analisadas em Ganhos e Perdas entre 1985 e 2017 Perdas (em vermelho) e ganhos (em verde)

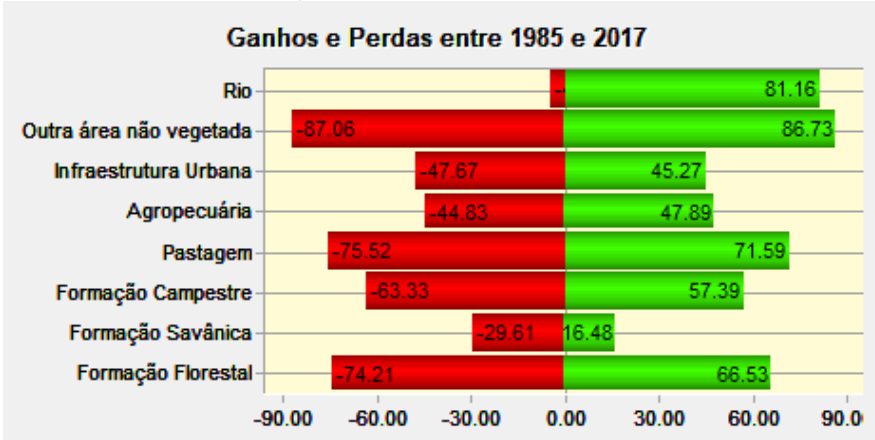

Elaboração: Iolanda Santos de Castro \& Lucas Amorim, 2019

Por meio dos dados analisados, verificou-se que as mudanças na formação florestal para as classes de uso da terra. As principais perdas da caatinga estão associadas ao crescimento expressivo da agropecuária entre o ano de 1985 a 2017, cerca de 117.183 
hectares, pode se verificar o desmatamento expressivo dessa região para as atividades agropastoris, pois a redução da vegetação natural é intensa (Figura 4).

Figura 4 - Classes analisadas em Hectares entre 1985 e 2017 Perdas (em vermelho) e ganhos (em verde)

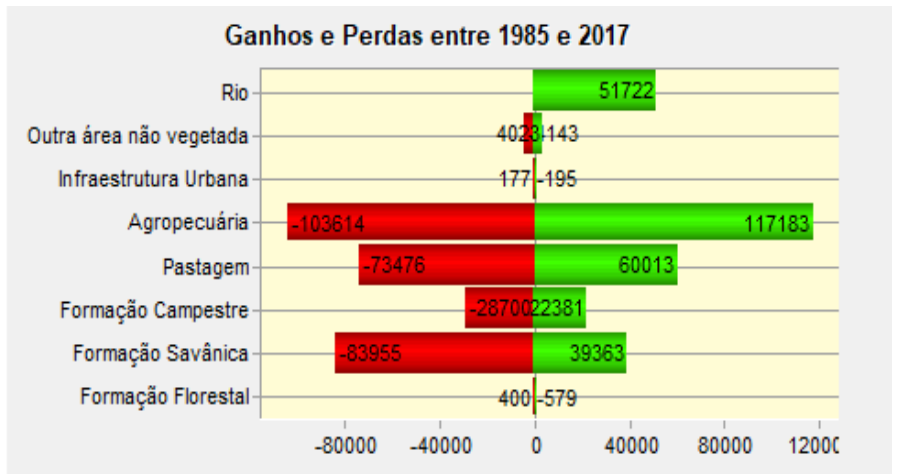

Elaboração: Iolanda Santos de Castro \& Lucas Amorim, 2019

Verifica-se também que a Infraestrutura urbana substituiu a formação florestal cerca de 195 hectares, esse avanço pode-se relacionar ao aumento da população.

\section{CONSIDERAÇÕES FINAIS}

Apesar de alguns malefícios advindo do represamento do lago, houve uma melhoria significativa a partir da década de 1980 para os pescadores e agricultores da região, haja vista que a construção do reservatório do Lago de Itaparica finalizava-se nessa década, o que possibilitou compreender que a plantação do coco e de outras culturas tenham iniciado anos depois já que as mesmas são cultivadas às margens do Lago, além do aumento da pesca, organização social e benefícios sociais.

Sendo assim, as mudanças detectadas que ocorreram na área de estudo foi o aumento significativo em hectares da classe da agropecuária, em contrapartida, nota-se a supressão da vegetação natural, sendo ocupada por agricultura e pastagem entre o ano de 1985 e 2017. Assim, para a proteção da região é importante a conscientização e sensibilidade da sociedade primam por uma nova visão de sustentabilidade e preservação do meio ambiente.

\section{REFERÊNCIAS}

CARDOSO, A.S. et al. Análise da presença do fitoplâncton em bacia integrante do Projeto de Integração do Rio São Francisco, região semiárida, Nordeste brasileiro. Eng Sanit Ambient, v.22 n.2, mar/abr 2017, p. 261-269.

ESTEVES, F.A. Fundamentos de limnologia. 3. Ed. Rio de Janeiro: Inderciência. 2011.

LOPES, H.; SOBRAL, M.C.; GUNKEL, G.; CANDEIAS, A.L.; MELO, G. Comportamento espacial da clorofila-a no reservatório de Itaparica, rio São Francisco. Revista Engenharia Sanitária Ambiental, v.20 n.3. 2015. p. 475-484. Disponível em DOI: 10.1590/S141341522015020000111066. Acesso em 10 de março, 2018.

MELO, G.L. Estudo da qualidade da água no reservatório de Itaparica localizado na Bacia do Rio São Francisco. Dissertação, 97f.Programa de Pós-Graduação em Engenharia Civil. Universidade Federal de Pernambuco, Recife - PE. 2007. 